\title{
Alzheimer and self-awareness: the awakening through art
}

\author{
Giorgio Bordin
}

Received: 13 September 2011 / Accepted: 11 October 2011/Published online: 18 November 2011

(c) Springer-Verlag 2011

William Utermohlen (1933-2007), Self-portrait, 1967; Self.portrait, 1997; A head, 2000. Private collection, New York Academy of Medicine.

A retaliation for longevity is the increase in some chronic diseases. Among them, dementia involves the destruction of personality. In each chronic disease, the caregiver bares the weight of the care for his relative, but in dementia, the family ties become gradually weaker, and the relationship appears less meaningful as time goes by. The value of the "self" in Alzheimer's disease seems lost. The perception of a poor quality of life leads to the "logical" conclusion that life itself has lost its dignity.

Apuleius (Rome, 125-170 AD) wrote: “... for madness cannot know itself any more than blindness can see itself". But when William Utermohlen learned in 1995 he had Alzheimer's, he began to try to paint autoportraits to better understand what was happening to him, the nature of his disease, as well as to retain self-awareness. The first selfportrait (made on his 34) is enlivened with a penetrating and determined expression; the 1997 work, done after 2 years of illness, shows emptiness and nothingness, both in the face as in the surrounding background. Suffering and aloneness are highlighted by the black blade of the saw on the right, which has no apparent reason, no relation and no texture with the man: decorative rather than substantial piece in the work, it is an empty black, framing the color of the life. In the third painting shown here ("A head, 2000"), the human face and his identity are almost completely lost,

G. Bordin $(\bowtie)$

Hospital Piccole Figlie, Parma, Italy

e-mail: gbordinas@inwind.it except for those two eyes, still looking around to grasp a meaning in a foreign environment. The artist died in 2007 and even his latest works offer, however, a personal witness of the truth of the persistence of his self-perception,

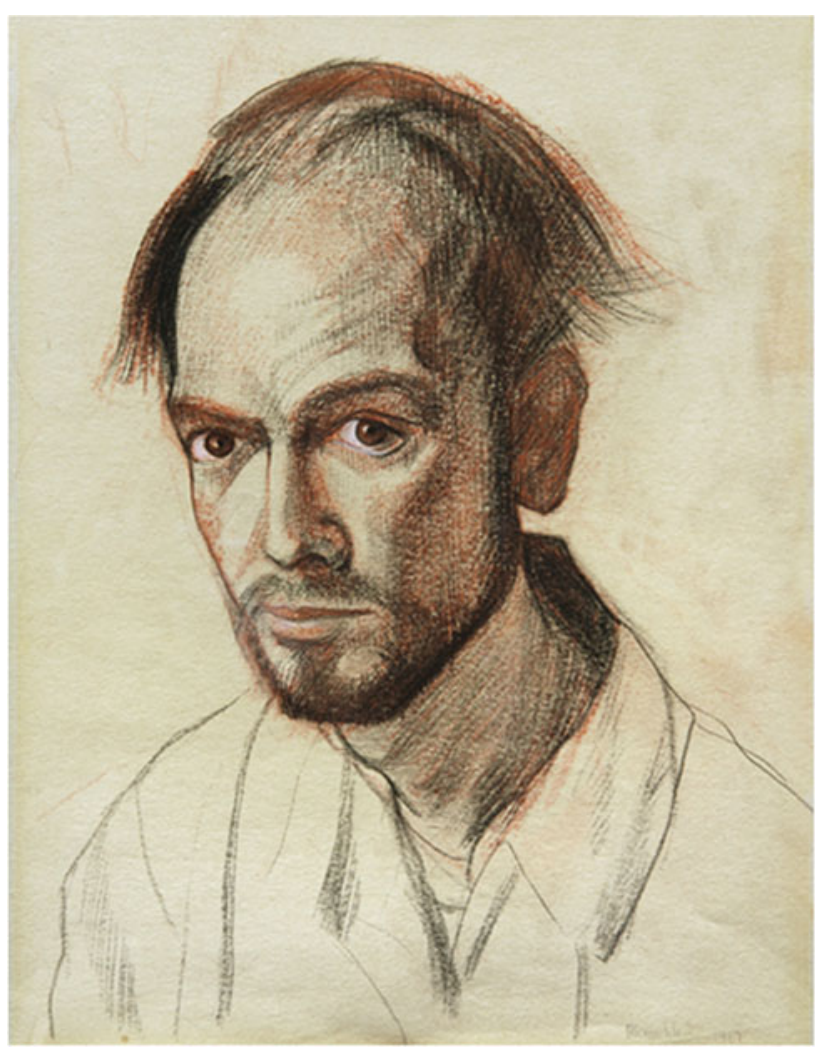

William Utermohlen. Self portrait: 1967 (drawing on paper). (C) Galerie Beckel-Odille-Boicos 2011 
unexpressed within the routine pathways of communication. The title of a symposium organized around the painter's work recalls this possibility of a perception that appears otherwise impossible: "Awakening Awareness through Art".

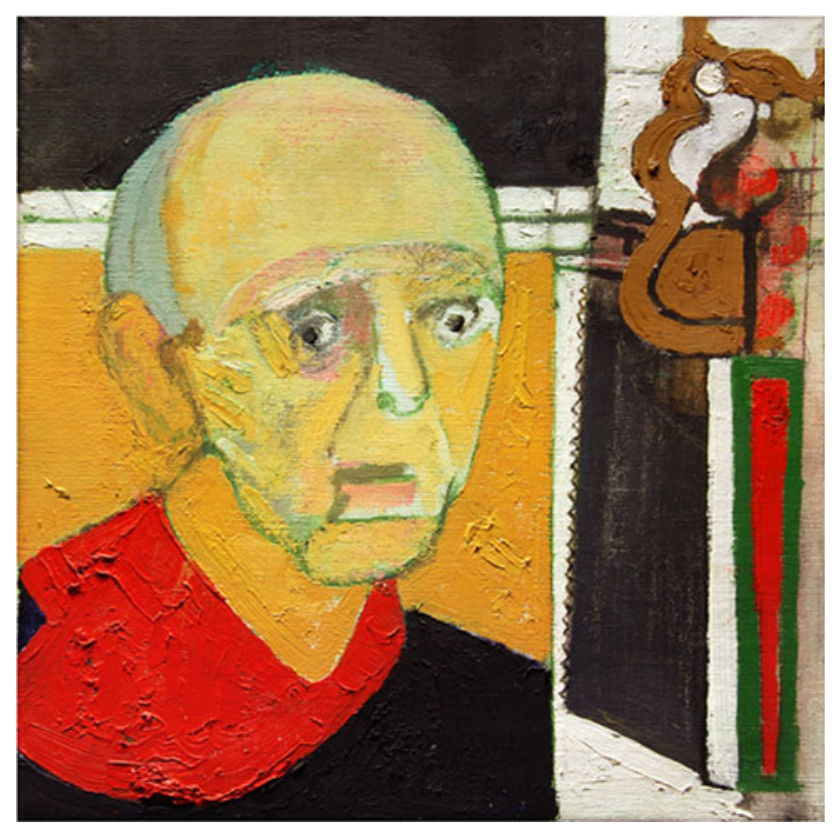

William Utermohlen. Self portrait: 1997 (oil on canvas). (C) Galerie Beckel-Odille-Boicos 2011

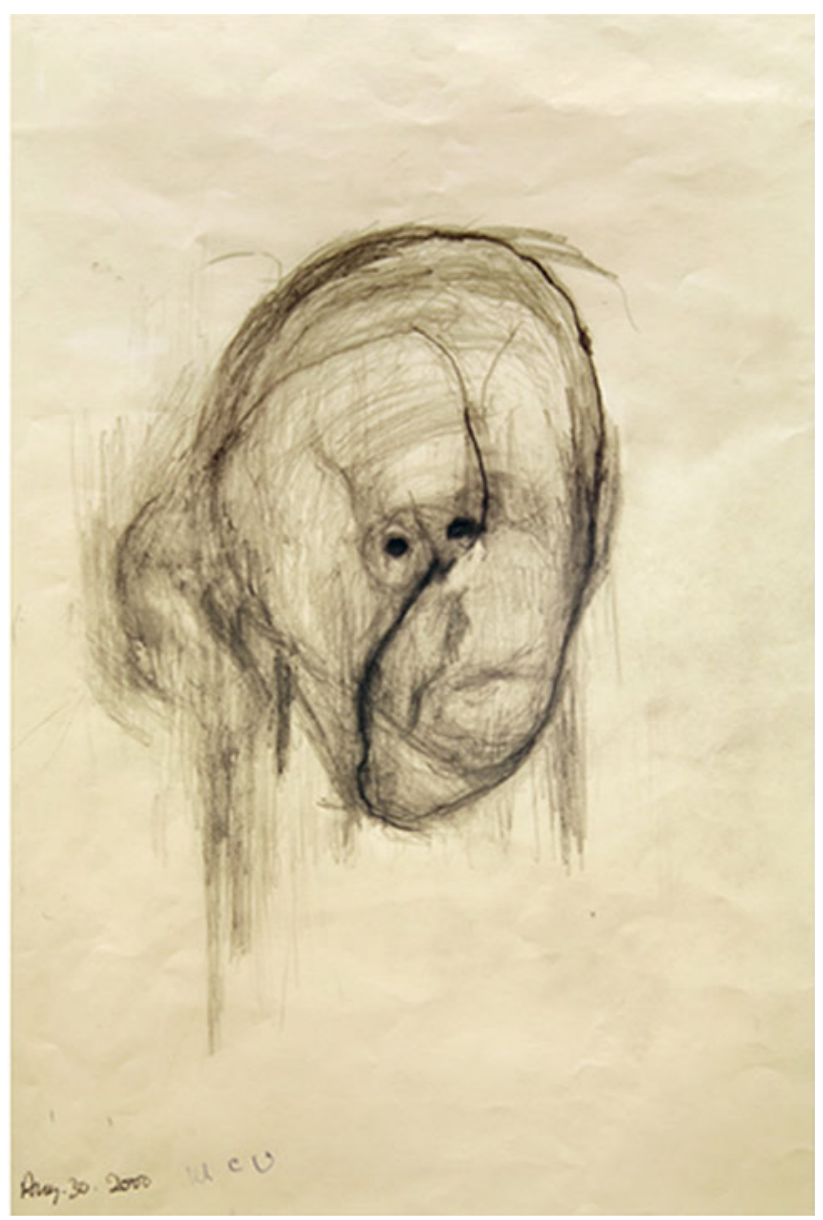

William Utermohlen. Self portrait: 2000 (drawing on paper). (C) Galerie Beckel-Odille-Boicos 2011 